\title{
Hoekpale van Gereformeerd wees
}

\section{Kernwaarhede van die Gereformeerde leer ${ }^{1}$}

Tjaart van der Walt

Gereformeerde Kerk Wapadrant

PRETORIA

\begin{abstract}
Core truths of being Reformed

The theme of the 1996 AGM of the GTV was "Reformed Dynamics Today!" This paper is the opening address, supposed, according to the programme, to be on "Fundamental truths of the Reformed faith." The author, however, preferred to call it "Core truths of being Reformed", reflecting a more dymamic, existential and inclusive approach.

In addition to three classical descriptions of what being Reformed means, attention is given to Biblical concepts that over the years played an important part in Reformed theological reflection and lifestyle. However, what really makes a difference, is not simply to tabulate "fundamental truths of the Reformed faith". The critical question is: What do we do with those fundamemal truths? Do we share them with other people? What is the perspective on the future that it opens up? Does it help us to get rid of the taboos of the past? Does it enable us to walk freely in the wide expanse of (jod's grace?
\end{abstract}

\section{- Tydgees}

Tydgees deur die eeue het my nog altyd geweldig geboei. As iemand op soek is na ' $n$ navorsingstema wat net so aktueel is as wat dit boeiend is, hier is een.

Die Tweede Wêreldoorlog het 'n dramatiese verandering in die geestesklimaat van ons stamland van weleer, Nederland, veroorsaak, al het sommige van die simptome, merkwaardig genoeg, eers later werklik deurgebreek. Ook die kerklike lewe, nie in die minste nie in gereformeerde geledere, is ten diepste daardeur geraak. Wat kan ons in Suid-Afrika uit die Nederlandse ervaring leer met die oog op die oorgang Ou na Nuwe Suid-Afrika (en alles wat daannee saamhang) en die impak van al hierdie veranderinge op ons geestelike lewe, ook op die kerke alhier?

I Voordrag geleuer tydens die Jaarvergadering van die GTV te Pretorıa op 6 Augustus 1996 
Allerhande identiteitsvrae is in elk geval al lank voor 27 April 1994 of 2 Februarie 1990 op die agenda. Wie en wat is die Afrikaner? Waarom Gereformeerd? Trouens, wat is Gereformeerd? Identiteitsvrae dui dikwels op 'n identiteitskrisis. 'n Mens vra nie wie of wat jy is as jy dit weet en buitendien geen twyfel het oor die waarom of die waarheen nie.

Eerlike vrae hoef nie op paniekerigheid te dui nie. Oneerlike antwoorde wel. Of as 'n mens jou veilig geborge voel in die ydele herhaal van die geykte dierbaarhede van gister en eergister, of as jy jou stokflou hardloop agter elke wind van verandering, en hyg-hyg jou verbeel dat jy darem by is.

'n Mens red nie die wêreld deur konferensies te hou nie. Daarteenoor, as besinningsgeleenthede soos dié van vandag meer kan wees as harsinggimnastiek of oor en weer vlieëvangery, kan ons taak môre en oormôre soveel duideliker wees.

\section{- Gereformeerde dinamika vandag}

Aan 'n beter tema juis vir so 'n geleentheid kan ek nouliks dink: Gereformeerde dinamika vandag! Oer-stoer, sonder meer, net bloot, enkel: Gereformeerd. Maar dan dinamies, sprankelend-bruisend van energie, hier en nou, eietyds, vandag

Dis die moeite werd om dieper op hierdie tema in te boor. Dis 'n tema wat by wyse van spreke wydsbeen staan oor ons dikwels nogal aardig gesplete bestaan. Want so is ons: behoudend tot en met (soms tot verstarring toe); aan die ander kant terdeè daarvan bewus dat veranderıngs in ons ou wêreldjie so vinnig toeslaan dat enige poging om by te bly al te maklik in krisisbestuur ontaard. En tog: wie in die werklik basiese dinge van die lewe waaragtig konserwatief is, het die krag, die moed, die energie om adembenewend progressief te wees in die wyse waarop hy (of sy) eeue-oue beginsels vars en fris uitleef in 'n dol-snel veranderende wêreld. 'n Aantal jare gelede het ek die kemslagspreuk "verankerde voorposdenke" amper te veel gebruik. Tóé en nóú se slagspreuk het egter verband met mekaar: Verankerde voorposdenke skakel inderdaad met Gereformeerde dinamika vandag - net, dit gaan nie soseer oor die dink nie, maar veral ook oor die dóén

Nie dat 'n mens ekskuus hoef te vra omdat jy eers dink voordat jy doen nie. Vir sommige mag dit dalk 'n bietjie ouderwets lyk, maar tog is dit 'n nogal aardig beproefde werkwyse. Goeie teorie maak die pad oop vir goeie praktyk, of in attestasietaal: suiwer in die leer, onberispelik in die lewe. Is dit nie dalk waarom egte gevoelsbelewenis van godsdiens soms ontaard: as dit nie ook deur die poort van die verstand gaan nie? 


\section{- Kernwaarhede: hoekpale}

Tog het ek 'n oomblik asem ingehou toe ek hoor dat die oorhoofse tema Gereformeerde dinamika vandag! is, maar dat my opdrag "Kernwaarhede van die Gereformeerde leer" is - nie dat ek enigsins iets het teen kermwaarhede nie, laat staan nog Gereformeerde kernwaarhede. Net, kom ons dink tog asseblief nie te gerieflik aan abstrakte waarhede wat vryblywend sweef (oftewel in die lug hang) oor 'n aarde wat na ons smaak nog al maar deur tohoe wabohoe woes en leeg is nie - veral in hierdie ding wat Nuwe Suid-Afrika genoem word nie.

Beginsels - ook grondbeginsels, kernwaarhede - hét hande en voete. Hulle loop. Hulle werk. Geloof is iets wat 'n mens kan sien, al is geloof self ook om die onsienlike te sien. Dis waarom ek, in plaas van bloot kernwaarhede, graag ook van Gereformeerde hoekpale praat. Hoekpale baken af: daar is ruimte, maar ook begrensing.

\section{- Aksentverskuiwing}

Ek het vroeèr vlugtig na die tydgees venwys. Nie eers van nou die dag af nie maar al 'n paar dekades lank is daar 'n aksentverskuiwing aan die gang - 'n verskuiwing van leer na lewe, van teorie na praktyk, van die abstrakte na die konkrete, van objektiewe waarhede na subjektiewe belewing. Natuurlik is dit eensydig, soos die tydgees vroeer ook sy eensydighede gehad het. Maar dis die wêreld waarin ons lewe, waarin ook "kernwaarhede van die Gereformeerde leer" moet funksioneer.

In elk geval, as hierdie kernwaarhede net in ons verstand bly rondomtalie sonder om ons harte warm te maak en ons hande en voete te laat jeuk, is ons finaal op pad na 'n Gereformeerde dinosaurusland, met ons kernwaarhede nog altyd suiwer by ons - net, hulle is, soos ons, gefossileer. Wat 'n kragsentrale moes wees, het 'n museum geword. Die vonk móét oorspring van hoof na hart, en die bloedsomloop kan dit dan deur die hele liggaam laat sirkuleer.

\section{- Wat máák ons met die kernwaarhede?}

Vroeèr sou ek ongemaklik gevoel het omdat ek nog nie werklik by die punt uitgekom het nie. Wat is hierdie Gereformeerde kemwaarhede? Sit hulle op tafel; moenie al rondom hulle bly praat nie!

Die belangrikste bydrae wat ek vandag kan maak, is nie om grondbeginsels te tabuleer en te rubriseer nie. Natuurlik moet ' $n$ mens jou gereeld vergewis van wat die hoofsaak, wat die kern is waarom dit gaan. Maar daaroor hoef ons nie konferensie te hou nie. Dis nie wat, altans in ons geledere, die geeste skei of die gemoedere laat oorkook nie. 
Wat máák ons met hierdie kernwaarhede? Hoe pas ons hierdie grondbeginsels toe? Hoe trek ons hierdie fundamentele lyne deur? Hoe deel ons hierdie geloofsbelewenisse met ander, ook met ander wat anders is?

Dis wesensvrae wat ek nie gerieflikheidshalwe op ander mag (of wil) afskuif nie. In my oënskynlike rond-en-bont pratery het ek van verskillende kante af hierdie punt probeer inskerp: kernwaarhede hang nooit in die lug nie, veral nie as dit kernwaarhede is van die Gereformeerde leer nie. Hulle vat grond - die vraag is wel: Hoe? En waar? En waarheen?

Ook in hierdie opsig is daar nie soveel nuuts onder die son nie. Die vrae kom in nuwe gewade op ons aan, maar sommige van die grondtrekke bly dieselfde. Wat is die kontinuiteit in die diskontinuitteit? Wat is die grense van die verskeidenheid waarin die basiese eenheid na vore kan tree sonder om self versnipper te word? Hoe ouderwets kan ouderwets bly sonder om die evangelie te verstar en wêreldvreemd te word? Hoe byderwets kan byderwets wees sonder om die evangelie te verwater en wêreldgelykvormig te word?

\section{- Moenie eksklusief dink ten opsigte van kernwaarhede nie}

Daar was al Doppers voor die Dopperkerk gestig (of dan herstig) is. Alle gereformeerdes het nie opgegaan in die Gereformecrde Kerk nie. Kom ons waak uitdruklik daarteen om eksklusief te dink as dit gaan om kernwaarhede van die Gereformeerde leer: hoe óns dit belewe, wat óns daarmee doen. Al gaan dit nie by hierdie geleentheid om die kerklike eenheidsvraag in die institusionele sin van die woord nie, van die plig - en voorreg - van "saam met al die heiliges", kom ons nie weg nie. Terloops, is ons eerlik as ons in die Openlike Verklaring by elke meerdere vergadering geesgenote oproep tot kerklike gemeenskap, en selfs praat van die "innigste broederlike gemeenskap" - maar as ons lidmate oor en weer begin oorloop, te naby aan mekaar kom, dan raak ons bekommerd? Gaan dit altyd om gesonde kerkbesef - of is dit partykeer pure kerkisme?

Tweedens: Die verskil tussen sentrum en periferie is duidelik, altans in teorie. Oor wat presies hoofsaak en wat bysaak is, is daar dikwels verskil. "Kernwaarhede" impliseer nie uitsluiting of minimalisering van ander "waarhede" nie. Om dit ouderwets-tegnies te stel: dit gaan om konsentrasie, nie reduksie nie. Die bedoeling is nie: vergeet die res - dis nie so belangrik nie, maar wel: as dit puntjie by paaltjie kom, is dit waaroor dit gaan

\section{- Gereformeerd wees is 'n proses}

Daar is drie klassieke maniere om Gereformeerd wees te omskryf, of dan minstens 'n wesenstrek (of wesenstrekke) te tipeer. 
Die eerste is die kortste: Ecclesia reformata semper reformanda. Gereformeerd wees is me iets staties nie, dis nie 'n eindproduk nie. Gereformeerd wees is 'n voortdurende proses waarin dinge nooit altyd maar dieselfde kan bly nie.

Hoe gerat is ons vir verandering - geestelik, ook organisatories? Hoe bereid is ons tot selfondersoek? Hoe oop is ons vir kritiek - of is ons nogal gou op ons perdjie?

Natuurlik gaan dit nie bloot om verandering ter wille van verandering nie, maar verandering om te verbeter, om reg te kom en reg te bly. In elk geval: Gereformeerd wees is alles behalwe staties: hou wat jy het; bly wat jy is. 'n Oertrek van Gereformeerd wees is 'n geweldige dinamiek: Ecclesia reformata semper reformanda.

\section{- Reformeer in leer, diens en tug}

Wat die kerk betref, word reformasie gewoonlik op drie terreine toegespits: leer, diens en tug (art. 29 NGB). Kemagtig:

- leer: Wat word daar gepreek?

- diens: Hoe word die erediens ingerig?

- tug: Hou die kerkraad effektief toesig? Werk sensuur?

Gereformeerd wees is meer as kerkwees, ook meer as Gereformeerde Kerk wees. Hierdie drie kriteria kan - en moet - onder meer soos volg verbreed word:

- leer: Is die preke Bybels - èn hoor ek net die preke, of lééf ek ook die preke? Weerspieël my lewe die suiwere leer? Is ek nie net ortodoks nie waar werklik ortopraks?

- diens: Dit kan tog nie net gaan oor die erediens, die skaars twee uur per week in die kerk wees nie - is die orige 166 uur elke week werklik aan God gewy?

- tug: Christen wees is nie vryblywend nie. Ek is my broeder se hoeder. Broers en susters vat hande, help mekaar op as een val. Ware tug begin by selftug. Hoe beheers ek myself? Tug is basies positief. Wat is mý bydrae tot die gemeenskap van die heiliges?

\section{- Gaan terug na die bron}

In ons voelvlug oor die drie terreine (leer, diens en tug) waarop die basiese patroon van "altyd reformeer" by uitstek toegepas moet word, het ons onvermydelik reeds die derde klassieke uitdrukking van Gereformeerd wees 
aangesny: die fundamentele norme, die absolute maatstawwe. Hoe meet 'n mens Gereformeerd wees? Wat is die toets, die kriteria - nie maar net soos 'n klompie mense êrens op 'n sekere tydstip voel nie, of soos 'n mens in jou verskillende lewensfases verskillende smake ontwikkel nie, maar soos dit die toets van die tyd oor die eeue been deurstaan het? (Met respek teenoor Charles Glass: hier gaan dit nog meer oor the taste that stood the test of time.)

Die Reformasie van die sestiende eeu wou nie iets nuuts skep nie, maar wou werklik teruggaan na die bron. Om 'n sêding van latere kritici te gebruik: Nie terug na Johannes Calvyn nie, maar terug na 'n ander JC: Jesus Christus.

Die grondtrekke van die Reformasie word skitterend saamgevat in die vier solismes:

- sola Sacra Scriptura

- sola gratia

- sola fide

- soli Deo gloria

Of dan vry vertaal in gewone Afrikaans:

- alleen op grond van die Bybel

- alles is genade

- slegs deur geloof

- net tot eer van God

\section{- Alleen op grond van die Heilige Skrif}

Leer by mekaar. Luister na jou gewete. Put uit jou ondervinding. Doen navorsing. Werk wetenskaplik. Stel vraelyste op. Doen eksperimente. Gebruik jou gesonde verstand. Hou rekening met die tradisie. Nie een van hierdie metodes gaan egter vir jou altyd onfeilbare antwoorde gee nie Uiteindelik is daar net een liniaal wat nooit buig of skeeftrek, nooit rek of krimp nie: die Bybel. Sola Sacra Scriptura. Alleen op grond van die Heilige Skrif.

\section{- Alles is genade}

Jy kan jou heel beste doen, maar dinge self regkry, sal jy nooit. Maar jy hóéf ook nie. Ten diepste is alles genade. God doen dit. Ook deur my, ja - maar ook sonder my, ondanks my. Ek het niks wat nie ten diepste vir my gegee is nie. Dis nie wat 'n kerk of sy lidmate doen wat die kritieke verskil maak nie, maar wat God doen. Sola gratıa Alles is genade. 


\section{- Slegs deur geloof}

Geloof, en geloof alleen, is die lewensband met God. Ander bande wat mense of kerke probeer lê, hou nie. Inteendeel. Hulle breek nie net vroeër of later nie; hulle verstrengel 'n mens so maklik. Werkheiligheid, moralisme, die wet van Moses of die kerkwet van die wie ook al, fatsoenlikheid as dit 'n leë dop geword het, of geesdrywery, eksklusiewe bekeringspatrone, die grootdoop of die Saterdagsabbat, die millennium en die wegraping, beswyminge en wartaalgebrabbel, of wat ook al. Enige sweem van: die kruis van Christus plus. Sola fide. Slegs deur geloof. Geloof by uitstek as daad, anker, lewensband, deur God gegee - en nie soseer as ding: 'n houer, 'n kolom, 'n tabel wat sê: dit en dit glo ek, nie

\section{- Net tot eer van God}

Maar - en dis van absoluut krities-beslissende belang - dit alles dan begrond en oorkoepel, omring en bepaal deur die vierde Solisme: soli Deo gloria; net tot eer van God. Want ten diepste is dit waaroor dit gaan: nie dat ek gelukkig moet voel of my heerlik kan uitlewe nie, maar dat God kry wat Hom oneindig keer toekom: die lof en aanbidding en danksegging van al wat leef en beef en sweef. Of om dit by wyse van voorbeeld op kerk wees toe te spits. Wie moet boweal in die kerk tuis voel: ek, of die Here?

\section{- Daarom}

Die genoemde kernfrases is inderdaad klassieke uitdrukkings van Gereformeerd wees - maar nog net so fris en vars as altyd, so raak.

Samevattend: Die basiese patroon is om altyd te reformeer. 'n Mens is nooit klaar met Gereformeerd wees nie. Gereformeerd wees is 'n proses, 'n lewenswyse

Die direk kritieke terreine van Gereformeerd wees, binne en buite die kerk, is leer, diens en tug.

- Preek ons die Bybel, en leef ons die Bybel?

- Dien ons God binne en buite die Kerk?

- Is ons werklik gemeenskap van die heiliges?

- Gee ons om vir mekaar, omdat ons omgee vir die Here?

Die vier grondpilare (of ook maatstawwe) is:

- die Bybel

- genade

- geloof 


\section{- die eer van God}

Dit dan wat die drie klassieke maniere betref om Gereformeerd wees te probeer beskrywe - of dan, om Gereformeerde kernwaarhede te formuleer, Gereformeerde hoekpale in te slaan.

Daar is ook ander maniere om 'n blik te kry op Gereformeerd wees. Hier is 'n paar, hopelik (maar nie gewaarborg nie) van die belangrikstes. Uit die Bybel. Uit die Kerkleer. Uit die filosofie. Uit die tradisionele lewenspatroon. En weer terug na die Bybel.

\section{- Watter Bybelse begrippe figureer by Gereformeerdes?}

As die Bybel dan nog altyd vir die Gereformeerdes so deurslaggewend was, watter Bybelse begrippe figureer by uitstek by hulle?

In die eerste plek loshande die verbond: dat die soewereine God Hom vrywillig, uit vrye welbehae, aan powere, nietige, nikswerd mensies verbind, en ook die pad oopmaak dat die omgekeerde gebeur: dat geslag na geslag vir die Here alleen sal leef. Die begrip is vroeg al as 'n Bybelse tema verwerk (op sy uitvoerigste hoewel nie die eerste nie - in Coccejus se Foederale Teologie). Veral in die opvoeding van ons kinders - in huis, kerk en skool - tree dit steeds sterk na vore.

Hoewel die teologiese verwerking daarvan eers veel later gekom het, was die Koninkryk van God van oudsher af vir Gereformeerdes sentraal. Dat Hy oor alles en almal vir altyd regeer, was immers vir hulle 'n kernsaak, al is die spesifieke terrein van sy heerskappy en die historiese dimensie daarvan nie altyd ewe duidelik verdiskonteer nie. Nietemin kon hulle met groot dankbaarheid in die vrugte, die gevolge, die seëninge van die heerskappy van God deel - en siedaar, die drie basiese betekenisvelde van die Bybelse begrip, die Koninkryk van God.

Ander Bybelse sleutelbegrippe het miskien nie noodwendig regstreeks uit die Skrif nie en dalk meer vanuit die kerkleer in die bloedsomloop van die Gereformeerdes begin sirkuleer. Hier dink 'n mens aan begrippe soos die Asellas Dei: dat die soewereine God niks en niemand nodig het nie - of predestinasie: dat Hy vooraf alles besluit en bepaal het. Ek sal bly wees as ek verkeerd is, maar ek het die indruk dat uitverkiesing meer negatief gefigureer het, in die sin dat dit teenoor vorme van Neo-Pelagianisme soos die Metodisme verdedig is, eerder as dat dit 'n positiewe, bevrydende rol in die geloofslewe gespeel het.

Ons voorvaders het wel baie troos uit die voorsienigheid van (jod geput, maar al het dit nie noodwendig tot gelatenheid of passiwiteit gelei nie, was daar ongelukkig nie altyd die sprankelende blymoedigheid wat 'n mens sou verwag van iemand wat welbewus leef as kind van die Allerhongste nie. Die grootheid 
van God was so oorweldigend dat sy liefde vir ons amper te menslik gelyk het om te veel daaroor te praat. Of meer teologies gestel, die aksent was sterker op die transendensie as die immanensie van God.

Die spesifiek-Calvinistiese filosofie is van vry resente datum. By wyse van ook daar kers opsteek, noem ek net die drie spore:

- Wysbegeerte van die Wetsidee (Dooyeweerd en Vollenhoven)

- Wysbegeerte van die Skeppingsidee (Stoker)

- Wysbegeerte van die Openbaringsidee (Bavinck)

En daar is nog drie Bybelse kernbegrippe: Wet, skepping, openbaring - wat in hulle funksionering ' $n$ legio ander kembegrippe op die doek laat verskyn, van die meer filosofiese soewereiniteit en universaliteit in eie kring, tot egte Bybelse mylpale soos skepping en herskepping, belydenis en vergifnis, vervulling en voleinding.

\section{- 'n Tradisioneel Gereformeerde lewenstyl}

Die noue band tussen leer en lewe is kenmerkend van Gereformeerd wees Vanuit die tradisionele Gereformeerde lewenstyl sou 'n mens dus met vug aanvullende peilings kon maak op wat Gereformeerde kernwaarhede behoor te wees, of dan minstens Gereformeerde hoekpale. Toegegee, dis 'n uitermate subjektiewe onderneming, en wat hier volg, is weinig meer as ' $n$ paar steekproewe by wyse van voorbeeld.

Vergelykenderwys gesproke het Gereformeerdes nog altyd uitgemunt in hulle kennis van die Skrif, die belydenis en ook die kerkorde. Insgelyks in die konsekwentheid van hulle optrede, soms selfs tot die rigoristiese toe. Opvallend was die soberheid en dissipline, ook die selfdissipline, wat maklik as 'n strengheid gekarikaturiseer is. 'n Sterk gemeenskapsbesef in die eerste plek tussen die Dopperfamilie onderling, maar ook wyer in die vorm van 'n Afrikanervolksgevoel, 'n duidelike nasionalisme en patriotisme, selfs tot die onkritiese toe, is verder kenmerkend. Dit alles gedra deur 'n opvallende roepingsbesef: ons is nie bloot op 'n horisontale plat vlak met bloot menslike dinge besig nie.

Die skadusy is dat die verstand meermale sterker betrek is as die hart. Die aksent op die leer het nie die lewe in die slag laat bly nie, maar wel die belewing van die godsdienswaarhede wat soms amper klinies gedissekteer is. Van die Afskeiding is in sekere kringe ' $n$ aksent op bevindelikheid geërf, meermale egter nie sonder die agtergrond van 'n swaarmoedigheid nie. Nie dat die persoonlike element ooit ontbreek het nie, net, dit is asof dit vir ons voorouers makliker was om te sê: "My Here en My God" as "My Vader" Die Middelaar was meer "Christus, ons 
Here" as "Jesus, ons Verlosser". En die Heilige Gees? Was dit die weerstand teen geesdrywery wat dit soms laat lyk het of ons vaders ietwat verlee is met die Gees? Daar was altyd 'n sterk weerstand teen die rasionalisme van bepaalde teologieë. Miskien was die afkeer teen emosionalisme ook op nie-teologiese vlak nog sterker.

Nogtans, 'n lewenstyl om jaloers op te wees, hoe ouderwets dit meermale ook mag gelyk het.

\section{- Strategiese Skrifgedeeltes in ons Gereformeerde erfenis}

'n Laaste hoek om perspektief op ons Gereformeerde erfenis te probeer kry: strategiese Skrifgedeeltes. Ons voorouers sou die laaste wees om voor die versoeking van 'n Bybel in die Bybel te swig. Vir hulle het dit voortdurend gegaan om die volle evangelie, die hele raad van God, die ganse Skrif. Afgesien van die veel wyer verspreide neiging om te maklik is-gelyk-aan-tekens tussen hulle tyd en Ou-Testamentiese gedeeltes te plaas - ek praat nou meer spesifiek van Gereformeerdes in ons Suid-Afrikaanse konteks, maar ook Gereformeerdes in ander wêrelddele het aan hierdie kwaal nie ontkom nie - is daar gedeeltes van die Nuwe Testament wat van kleintyd af deel van my rypwordingsproses was. Wat ek oorgehou het - en dis uiteraard heel subjektief - is veral:

Romeine 11:36: Uit Hom en deur Hom en tot Hom is alle dinge. Aan Hom behoort die heerlikheid tot in ewigheid! Amen.

1 Korintièrs 10:31: Of julle eet en of julle drink of wat julle ook al doen, doen alles tot eer van God.

Kolossense 3:23: Wat julle ook al doen, doen dit van harte soos vir die Here en nie vir mense nie

Maar die mooiste bly vir my persoonlik:

Romeine 14:7-9 Niemand van ons leef tog vir homself nie, en niemand sterf vir homself nie As ons lewe, leef ons tot eer van die Here; en as ons sterwe, sterf ons tot eer van die Here Of ons dan lewe en of ons sterwe, ons behoort aan die Here Hiervoor het Christus ook gesterf en weer lewend geword: om Here te wees van die dooies en die lewendes

Inderdaad 'n ryke erfenis

Wat máák ons daarmee? En wat doen dit aan ons? 


\section{- Wat impliseer Gereformeerde kernwaarhede?}

'n Blote herhaling of reproduksie van "kernwaarhede van die Gereformeerde leer" waarborg nog nie Gerefonneerde dinamika vandag nie. Inteendeel.

Daarom ten slotte 'n paar hardopdink-gedagtes oor hoe ons hierdie erfenis - of dan, minstens fasette daarvan - anders sou kon hanteer (en beleef!) as wat soms of tradisioneel die geval was. Want ook ons vaders het - hoe kon dit anders? nie aan die tydgees ontkom nie. 'n Uitdrukking of belewing van 'n "kernwaarheid" wat in hulle tyd vars en fris was, moes onvermydelik verlep as die wind van 'n ander tydgees daaroor waai. En buitendien, hoeveel keer sien 'n mens dit nie in die geskiedenis nie: Die élan van die eerste generasie van 'n deurbraak stol, verstyf, verstar, namate die epigone in die volgende geslagte hulle ywerig daarop toespits om die oorspronklike onberispelik te bewaar en pynlik noukeurig te reproduseer.

In die eerste plek die hele idee van "kemwaarhede" as sodanig. Te dikwels is hulle gesien as objektiewe groothede wat as't ware èrens 'n eie bestaan het, en van tyd tot tyd van die rak afgehaal, afgestof en geïmplementeer word. "Gereformeerde kernwaarhede" is nie bloot berigte ór God se genade nie, maar is self déél van sy genade. Hulle leef net in die dampkring van die evangelie, omdat hulle self deel is van die evangelie. Rooiligte flikker die oomblik as hierdie kemwaarhede filosofiese grondbeginsels of dogmatiese uitgangspunte word. Kernwaarhede floreer as hulle sirkuleer in die bloedsomloop van die Liggaam van Christus. Hulle is alles behalwe 'n spyskaart vir die selfvoldane fynproewer, opsies wat oop is na gelang van tyd of omstandighede.

"Kernwaarhede van die Gereformeerde leer" het swaar gely onder die skolastiek. Kernwaarhede kan alleen gedy as hulle multi-dimensioneel beleef word; as hulle tot ons kom deur die poorte van verstand, wil én emosie; as hulle spreek tot hoof, hart èn hand.

Kemwaarhede hoef nie ingewikkelder te word nie. Inteendeel - juis kinderliker, omdat God ons Vader is; vrymoediger, omdat Christus ons vryspraak is; reiner en helderder omdat die Heilige Gees ook by ons is, en ons bewus uit die Gees wil lewe.

Hierdie ingesteldheid beteken 'n sterker aksent op die persoonlike, nie soseer die abstrakte nie, op die belewing, nie bloot op die leer nie; op die funksionele, nie net die ontologiese nie. Wat máák ek met hierdie kernwaarhede - en wat dóén die kernwaarhede aan my? Dis twee kemurae. Hulle bestryk 'n veel wyer terrein, ek fokus ten opsigte van elk van hulle op een strategiese toespitsing. 


\section{- Deel hierdie kernwaarhede met ander}

Wat maak ons met hierdie kernwaarhede? Deel dit ook met ander! Moet dit nie net self beleef, self deurdink, self toepas nie - dra dit ook uit!

By Calvyn self was daar ' $n$ baie duidelike sendingbewustheid, en ook daadwerklike missionêre optrede. Uitsonderings daargelaat, 'n uitstaande kenmerk van latere gereformeerde geslagte - ook van die Gereformeerde Kerke in SuidAfrika - was dit helaas nie.

Bekommerd oor ' $n$ jeug wat neig om weg te dryf? Moenie hulle probeer terugpraat nie - gee hulle liewer die kans om saam te dóén. Deur "kernwaarhede van die Gereformeerde leer" met ander te deel, na ander uit te dra, sal dit steeds meer welbewus deel van hulle eie geesteskat en lewenswyse word.

\section{- Kernwaarhede laat my na vorentoe lewe}

Wat doen hierdie kernwaarhede aan my? Dit open by uitstek 'n toekomsperspektief vir my. Dit laat my vorentoe lewe. Vir baie gereformeerdes is en was godsdiens, behalwe opkyk na bo, 'n kwessie van terugkyk - terugkyk na God se magtige dade in die verlede. Maar wat van die toekoms?

Te dikwels was die eskatologie 'n stiefkind van die gereformeerde dogmatiek, 'n slothoofstuk wat volledigheidshalwe ook moes bykom, maar in werklikheid net sowel 'n bylae (om nie te sê byvoegsel nie) kon gewees het. Was dit omdat daar nie altyd werklik die besef was dat "die laaste dinge" al 2000 jaar gelede begin het, sodat eskatologie nie oor die esoteriese cendag gaan nie, maar wesenlik is om iets van die sin, die tendens, die golfslag van die geskiedenis ook hier en nou te begryp?

\section{- Ironieē van die geskiedenis, taboes van die verlede}

Geskiedenis het ook sy ironieè. Die Reformasie wou die Kerk van Christus van die juk van die Pous bevry - maar hoeveel pousies het nie skielik hulle verskyning gemaak nie? Papierpouse, byvoorbeeld in die vonn van kil-formalistiese binding aan oorywerige sinodebesluite. Pouse (of is dit pousies?) van vlees en bloed, in die vorm van kerkvorstelikhede - of gewoon plaaslik in die persepsie van die gemeente dat die dominee vir alles en nog wat die onmisbare sleutelrol moet vertolk - en hoe maklik gee van ons dominees nie aan hierdie druk toe nie! In 'n domineeskerk kan die amp van die gelowige, die priesterskap 'an al Gods kinders, onmoontlik gedy.

Ander taboes van die verlede het klaar verdwyn. Ons kan gerus ook hierdie een finaal die nek omdraai: dat ' $n$ mens dweep as jy oor die persoonlike van jou godsdiens praat. Waar kom ons aan hierdie beskroomde skugterheid, hierdie godsdiensblokkasie? Dit kan tog nie 'n erfenis van die Britse liberalisme wees 
nie, kompleet met hulle stelreël en al, dat godsdiens 'n persoonlike saak is, en dat 'n egte heer nie oor godsdiens of die politiek praat nie. Is dit vir die soveelste keer 'n reaksieverskynsel? Dat 'n mens, in reaksie teen die eksesse van 'n gespeel op die emosies, huiwerig is om self gevoel in jou godsdiens te wys? Dat ons so styf vasskop teen bidure wat maklik sou kon ontaard, dat ons die vrymoedigheid om te bid - behalwe plegtig-formeel in die openbaar of stoksielalleen in die binnekamer - verloor? Dat ons afwysing van mensgedrewe bekeringsprosedures ons eie persoonlike geloofsekerheid - of minstens ons vrymoedigheid om daaroor te praat - ernstig aan bande lê?

\section{- Die wydheid van Christen wees}

Teenoor alles wat as Christelik aangedui word, is dit sekerlik nodig om uitdruklik te sê wat ons onder Christelik verstaan - vandaar dan allerlei kwalifikasies soos Protestants, Calvinisties, of ook Gereformeerd. Dit mag egter hoegenaamd nie meebring dat ons die wydheid van doodgewoon ongekwalifiseerd Christen wees, prysgee nie. Kom ons tree na buite in die eerste plek as Christene op - en kom ons wys vir die mense met ons dade watter soort Christene ons is, eerder as om elke keer met woorde rekenskap te probeer gee van wat ons presies onder Christen wees verstaan.

Sien dit nie bloot as 'n pleidooi oor 'n stukke terminologie nie - sien dit ook as 'n algemene benadering "so wyd soos die Heer se genade." Elke sweem van 'n geslote klub wees, moet wortel en tak uitgeroei word; "saam met al die heiliges" (Ef. 3:18) moet ons lewenshouding wees.

\section{- Eenheid en veelheid}

Daar was 'n tyd (al weer die tydgees!) toe dit "in" was om amper tot die monolitiese toe in alles altyd dieselfde wees (nie net een in leer, diens en tug nie, maar eenders in leer, diens en tug). Kom ons beoefen die "gemeenskap van die heiliges" ook hierin dat ons mekaar meer vertrou, en daarom ook die vryheid gun om "kernwaarhede" op hulle eie manier te beleef, in hulle eie styl uit te druk. Waar kom ons aan die wantrouensuitgangspunt wat alles tot in die fynste besonderheidjie vir alles en almal wil voorskryf - asof die Gees nie ook Gods kinders in die waarheid kan lei van 'n eiesoortige en eietydse toepassing van duidelik uitgespelde en aanvaarde "kernwaarhede" nie?

Die Gees woon in die een liggaam van Christus, maar genadiglik het hierdie liggaam 'n verskeidenheid ledemate (1 Kor. 14). Nogtans word hulle almal deur die een Gees beheer. Net so is daar ' $n$ wyse reeks gawes, maar net een Gewer (Rom. 12). 


\section{Dinamika vanuit die Gees}

Ten diepste is juis dit, wat my betref, die belangrikste rede vir 'n gebrek aan "Gereformeerde dinamika vandag" - as daar nie welbewus dinamies uit die dunamis van die dinamo, die Heilige Gees, geleef word nie. Is die tussentyd, die tyd tussen die Koms en die Wederkoms, die tyd waarin ons nou lewe, nie uitdruklik die tyd van die Gees nie? En hoe oneindig meer is die Heilige Gees nie as alle tydsgeeste saam nie! 